3. Mumert ML, Altay T, Shelton C, et al. Ganglion cyst of the temporomandibular joint with intracranial extension in a patient presenting with seventh cranial nerve palsy. J Neurosurg 2012;116:310-2.

4. Silva EC, Guimaraes AL, Gomes CC, et al. Ganglion cyst of the temporomandibular joint. Br J Oral Maxillofac Surg 2005;43:77-80.

5. Akhter R, Morita M, Ekuni D, et al. Self-reported aural symptoms, headache and temporomandibular disorders in Japanese young adults. BMC Musculoskelet Disord $2013 ; 14: 58$

\section{Extra-Abdominal Desmoid Tumor Located in the Axilla}

Francisco Javier Pacheco Compaña ${ }^{1}$, Ángel Álvarez Jorge ${ }^{1}$, Carmen Delgado Sotorrío ${ }^{2}$

Departments of ${ }^{1}$ Plastic Surgery and ${ }^{2}$ Pathology, Complejo Hospitalario Universitario de A Coruna, A Coruna, Spain

Correspondence: Pacheco Compana Francisco Javier Department of Plastic Surgery, Complejo Hospitalario Universitario de A Coruna, Calle As Xubias, № 84. CP: 15006, A Coruna, Spain Tel: +34-651517226, Fax: +34-95270287

E-mail: javipacheco25@hotmail.com

No potential conflict of interest relevant to this article was reported.

Received: 4 Apr 2014 • Revised: 17 Jun 2014 • Accepted: 17 Jun 2014 pISSN: 2234-6163・ elSSN: 2234-6171

http://dx.doi.org/10.5999/aps.2014.41.6.780 • Arch Plast Surg 2014;41:780-782

Copyright (C) 2014 The Korean Society of Plastic and Reconstructive Surgeons This is an Open Access article distributed under the terms of the Creative Commons Attribution Non-Commercial License (http://creativecommons.org/licenses/by-nc/3.0) which permits unrestricted non-commercial use distribution, and reproduction in any medium, provided the original work is properly cited.

Desmoid tumors are rare benign tumors biologically classified between nonaggressive fibrous tumors and low-grade fibrosarcomas. On one hand, they present as infiltrating masses that might reappear if resection is incomplete, and on the other hand, they are composed

Fig. 1.

Chest computed tomography. The white arrow indicates the tumor. of well-differentiated fibroblasts that do not metastasize.

The aim of this paper is to present a case of desmoid tumor located in the axilla and a review of the related literature.

A 58-year-old woman was referred to our outpatient clinic because of pain in her right shoulder for 8 months. She underwent computed tomography (CT) (Fig. 1) and magnetic resonance imaging (MRI). They showed a mass of soft tissue in the right axillary region. There was suspicion of a soft tissue tumor, and an ultrasound-guided biopsy was carried out to confirm it. The ultrasound showed a hypoechoic tumor with a hyperechoic rim and an acoustic shadow. The biopsy revealed a spindle cell lesion with little atypia that suggested fibromatosis.

Surgical treatment revealed a soft tissue tumor that infiltrated one of the two axillary veins, the teres major muscle, the subscapularis muscle, and the latissimus dorsi muscle, without infiltration of the brachial plexus. A bloc resection of the tumor and the infiltrated structures was done (Fig. 2). The safety margin was approximately $2 \mathrm{~cm}$, but an intraoperative biopsy confirmed the presence of a tumor next to the plexus. A macroscopic study showed a mass of 7 $\mathrm{cm} \times 5 \mathrm{~cm} \times 4.5 \mathrm{~cm}$ with a tumor of $4 \mathrm{~cm} \times 4 \mathrm{~cm} \times 3$ $\mathrm{cm}$. It was whitish, firm, and rubbery with poorly defined margins (Fig. 3). The histopathological examination revealed a tumor composed of a proliferation of well-differentiated myofibroblasts with a low cell density and an infiltrative growth pattern. There were no cytologic findings of malignancy and less than one mitosis per high power field. However, the tumor was very locally aggressive as it infiltrated and destroyed the adjacent muscle and the adipose tissue (Fig. 4). In the immunohistochemical study, the tumor cells were positive for the mesenchymal marker vimentin (Fig. 5), focally positive for the muscle marker actin, and negative for CD34 and the S-100 protein. The Ki67 proliferative index was low, less than $5 \%$. With these results, the diagnosis was desmoid tumor. Because the tumor was near the excision margin, the patient was treated with a total dose of 54 Gy of postoperative radiotherapy. CT and ultrasoundguided biopsy were carried out with no evidence of recurrence five months after surgery. Nine months after surgery, the patient has no symptoms of recurrence.

The desmoid tumor is a rare benign tumor that presents as an aggressive musculoaponeurotic fibrosis $[1,2]$. It constitutes $0.03 \%$ of all tumors and $3 \%$ of soft- 


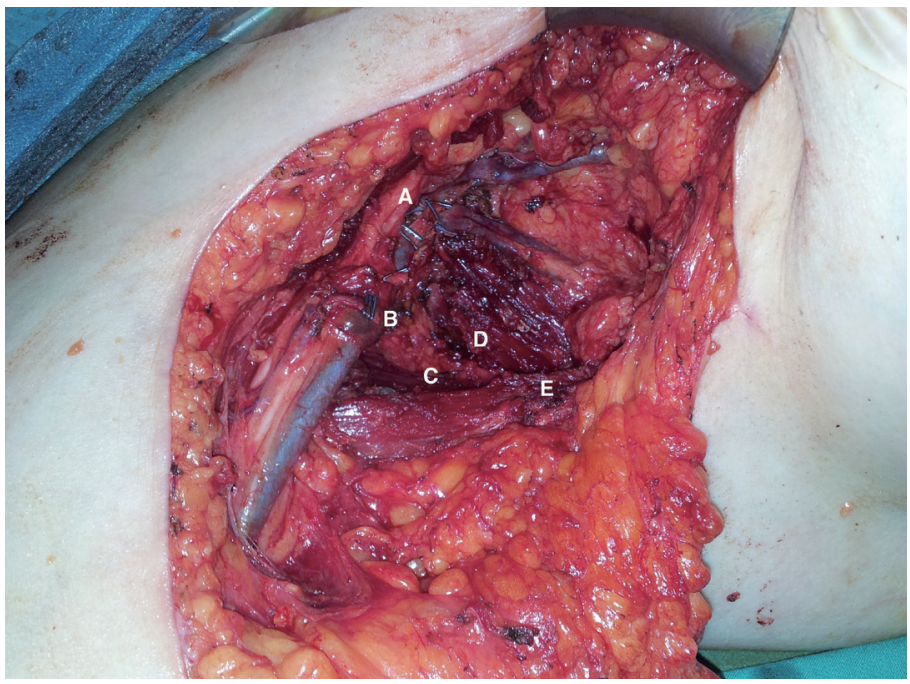

Fig. 2.

Axillary dissection after tumor resection. A skin incision was made in the axillary region and was extended to the inner arm. The axillary brachial plexus and vessels were dissected, which showed that one of the axillary veins was infiltrated. The teres major muscle, subscapularis muscle and latissimus dorsi muscle were also infiltrated. $A$, brachial plexus; $B$, axillary vein; $C$, teres major muscle; $D$, subscapularis muscle; $E_{1}$ latissimus dorsi muscle.

tissue tumors [1]. It is more frequent in women, most commonly in patients aged between 15 -year-old and 60 -year-old [2]. The high recurrence rate is associated with the fact that tumor cells tend to spread through the muscle fascia, which makes complete resection difficult [2].

Desmoid tumors can be classified according to their location into intra-abdominal, abdominal, and extraabdominal types. The abdominal desmoid tumor appears in the anterior abdominal wall, most commonly found in women during or after pregnancy. The intra-abdominal desmoid tumor is located in the mesentery or pelvic wall and is associated with familial adenomatous polyposis (Gardner's Syndrome). The extra-abdominal desmoid tumor is located in most of the cases in the upper limbs and shoulders. Multiple desmoid tumors are rare ( $15 \%$ of cases) [3]. There is a higher incidence in patients with trauma, previous surgery, family history of desmoid tumors, and changes in the basal hormonal status (pregnancy) [2]. Desmoid tumors appear as a mass hard in consistency that affects the soft tissue attached to the muscle. It may be associated with pain if it concerns neural structures [1]. The diagnosis is carried out by imaging techniques and confirmed by histology. The ultrasound shows a hypoechoic tumor, which is often accompanied by an acoustic shadow [2]. CT shows a mass with a consistency similar to the muscle, making it difficult to weighted imaging) [2].

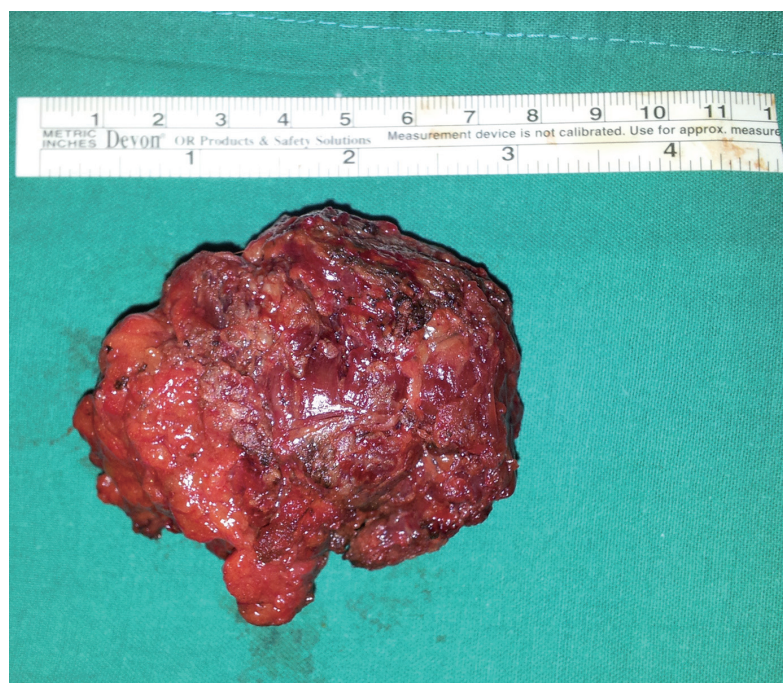

Fig. 3.

Resected tumor.

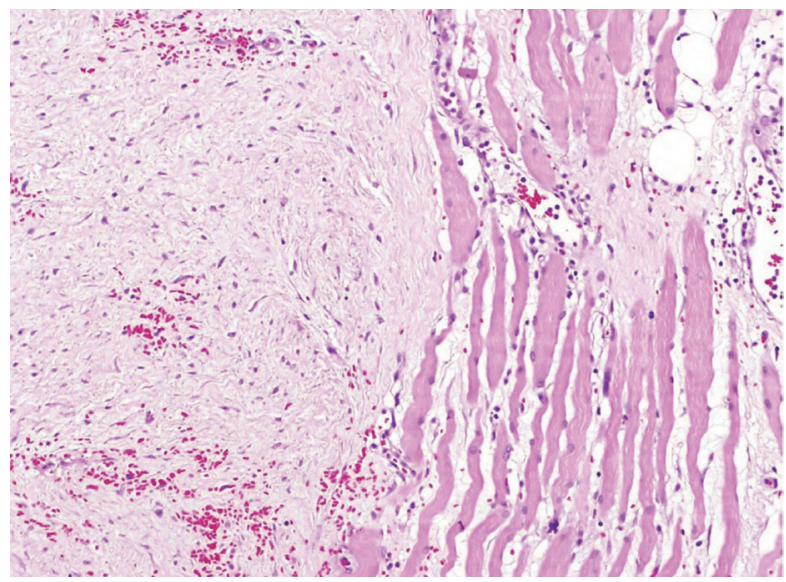

Fig. 4.

Histological study $(H \& E, \times 40)$. The tumor consists of a fibroblast proliferation (left), with a low cell density, infiltrating the muscle tissue (right) and the adjacent adipose tissue (upper right).

delineate the edges of the tumor. MRI is the preferred imaging technique as it allows us to distinguish the edges of the lesion more clearly (it appears iso-intense on T1-weighted imaging and hyper-intense in T2-

The histopathological examination shows a tumor with poorly defined margins that infiltrates the adjacent tissues. It consists of fibroblast-like spindle cells with benign cytologic features within a collagenous stroma. The differential diagnosis includes scarring processes, nodular fasciitis, solitary fibrous tumor, and low-grade fibrosarcoma. In the immunohistochemical study, the desmoid tumor is positive to vimentin and actin proteins and negative to CD34, S100, and CD117 (C-Kit). The immunoreactivity for nuclear beta- 


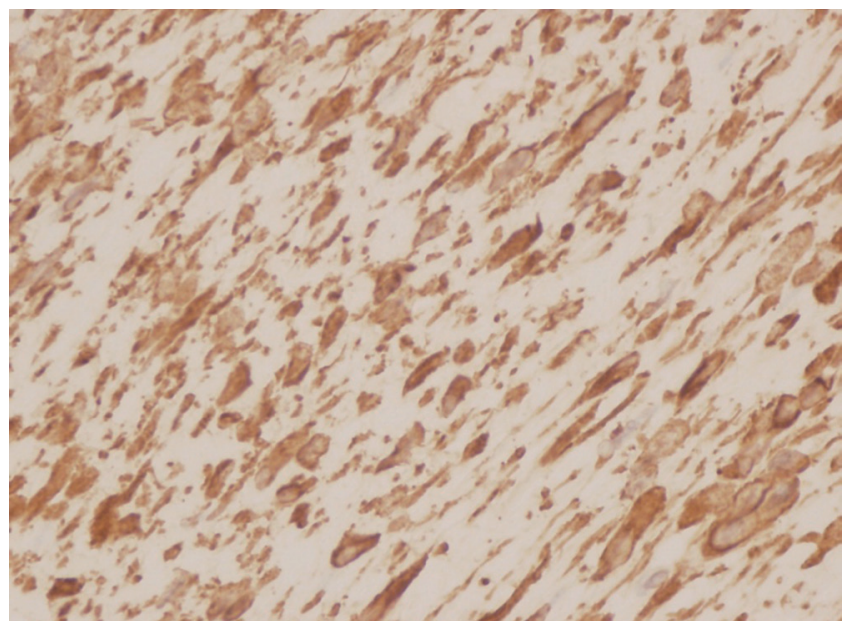

Fig. 5.

Immunohistochemical study (Vimentin, $\times 400)$. The tumor cells were positive for the mesenchymal marker vimentin.

catenin is variable but specific [4].

Surgical treatment is the technique of choice. It is necessary to perform a wide resection in order to decrease the recurrence rates. There is no consensus in determining how wide the excision margins must be in the resection as it is difficult to differentiate tumor tissue from healthy tissue [2]. Some authors suggest making the margin at least $2-3 \mathrm{~cm}$ wide [1]. These tumors present a high rate of recurrence (between $15 \%$ and $77 \%$ ) [2,3], particularly in cases where resection with wide margins is difficult, such as facial tumors. The use of postoperative radiotherapy is beneficial in the case of these tumors. The total recommended dose is 50-60 Gy [5]. Some published series show the usefulness of chemotherapeutic treatments in order to achieve a reduction in the tumor size. Some of these treatments are vincristine, methotrexate, doxorubicin, or imatinib [2]. Due to the fact that desmoid tumors have estrogen receptors, the possibility of associating hormonal therapy with tamoxifen for the treatment of these tumors has been raised [3].

In conclusion, the extra-abdominal desmoid tumor is a rare benign tumor that presents itself as an aggressive fibrosis of the musculoaponeurotic tissue. The treatment of choice is wide-margin surgical resection. In order to avoid recurrence, there are other forms of treatment, such as radiotherapy, chemotherapy, and hormonal therapy.

\section{References}

1. Dafford K, Kim D, Nelson A, et al. Extraabdominal desmoid tumors. Neurosurg Focus 2007;22:E21.

2. Molloy AP, Hutchinson B, O'Toole GC. Extra-abdominal desmoid tumours: a review of the literature. Sarcoma 2012;2012:578052.

3. Shinagare AB, Ramaiya NH, Jagannathan JP, et al. A to $\mathrm{Z}$ of desmoid tumors. AJR Am J Roentgenol 2011; 197:W1008-14.

4. Weiss SW, Goldblum JR. Fibromatoses. In: Weiss SW, Goldblum JR, editors. Enzinger and Weiss's soft tissue tumors. 5th ed. St. Louis: Mosby Elsevier; 2008. p.22755.

5. Schulz-Ertner D, Zierhut D, Mende U, et al. The role of radiation therapy in the management of desmoid tumors. Strahlenther Onkol 2002;178:78-83.

\section{A Giant Subpectoral Lipoma}

Jun Chul Shin ${ }^{1}$, Bum Sik Kang ${ }^{1}$, Woo Hoe Heo ${ }^{1}$, Keum Ha Choi ${ }^{2}$, Eun-A Kim ${ }^{3}$, Jeong Hoon Song ${ }^{1}$

Departments of ${ }^{1}$ Plastic and Reconstructive Surgery and ${ }^{2}$ Pathology, Wonkwang University School of Medicine, Iksan; ${ }^{3} U \& U$ Clinic, Iksan, Korea

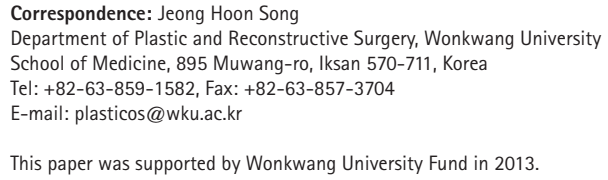

This article was presented as a poster at the 68th Congress of The Korean Society of Plastic and Reconstructive Surgeons on November 4-7, 2010 at Seoul, Korea.

No potential conflict of interest relevant to this article was reported.

Received: 2 Jul 2014 • Revised: 7 Aug 2014 • Accepted: 23 Aug 2014 pISSN: 2234-6163 • elSSN: 2234-6171

http://dx.doi.org/10.5999/aps.2014.41.6.782 • Arch Plast Surg 2014;41:782-784 Copyright (C) 2014 The Korean Society of Plastic and Reconstructive Surgeon This is an Open Access article distributed under the terms of the Creative Commons Attribution Non-Commercial License (http://creativecommons.org/licenses/by-nc/3.0/) which permits unrestricted non-commercial use, distribution, and reproduction in any medium, provided the original work is properly cited.

A lipoma is a common benign tumor of mesenchymal origin that can arise in any location where fat is normally present, with incidence of approximately $16 \%$ of all mesenchymal tumors. However, submuscular lipomas under the pectoralis major muscle are rare. And, because lipomas tend to be small, large lipomas are specifically called 'giant lipoma.' Giant lipoma is defined as a lipoma that is greater than $10 \mathrm{~cm}$ in any direction or greater than $1,000 \mathrm{~g}$ in weight $[1]$. 